\title{
35 USE OF ADVANCE CARE PLANNING - A EUROPEAN PERSPECTIVE
}

10.1136/bmjspcare-2011-000053.35

P Simón Lorda Granada University, Spain

Advance Care Planning (ACP) can be considered the second stage of a movement which tries to incorporate patient's decisions to end-of-life (EOL) healthcare decisions. The first stage is focused on the development of Advance Directives (ADs). Nowadays there is a broad consensus about the inadequacies of these written documents when they are filled and applied in a bureaucratic manner, disconnected of the clinical context and 
in absence of a communicative environment. ACP gives this more adequate perspective to the use of $\mathrm{ADs}$ and even can do without them because the end, the incorporation of patient's perspectives and wishes in EOL decisions, can be reached by other means. But in my opinion, it is not easy to reach the second stage without going first through the first stage, even doing it in a fast manner. So, the scarce development of ACP approach in Europe is coherent with the scarce development of ADs. The situation of ADs in Europe is characterized by its disparity between the different countries of the Region. We can find countries where specific laws on the issue have been adopted (UK, Austria, Spain, Hungary, Belgium, The Netherlands, Finland, France, Germany) and countries where there is no specific legislation (Greece, Italy, Norway, Bulgaria). But there are significant differences between all these regulations, for example in relation with the binding force of such documents. These differences between European countries help us to understand the great differences between ACP developments. Countries such us UK, Belgium, the Netherlands or Germany, with a strong regulation on $\mathrm{ADs}$ are developing the ACP approach in a fast manner. Spain has a particular status: broad legal development with low clinical impact and scarce development of ACP. 